\title{
A Novel, Fully Saturated Menaquinone from the Thermophilic, Sulphate-reducing Archaebacterium Archaeoglobus fulgidus
}

\author{
By B. J. TINDALL, ${ }^{*} \dagger$ K. O. STETTER ${ }^{2}$ AND M. D. COLLINS ${ }^{3}$ \\ ${ }^{1}$ Institut für Mikrobiologie, Rheinische Friedrich-Wilhelms-Universität, Meckenheimer Allee 168, \\ D-5300 Bonn 1, Federal Republic of Germany \\ ${ }^{2}$ Lehrstuhl für Mikrobiologie, Universität Regensburg, Universitätsstrasse 31, Postfach 397, \\ D-8400 Regensburg, Federal Republic of Germany \\ ${ }^{3}$ Department of Microbiology, AFRC Reading Laboratories, Shinfield, Reading RG2 $9 A T, U K$
}

(Received 17 June 1988; revised 4 October 1988; accepted 1 December 1988)

\begin{abstract}
A recently described extremely thermophilic, sulphate-reducing archaebacterium, Archaeoglobus fulgidus, was investigated for the presence of respiratory lipoquinones. Initial screening using thin-layer chromatography and UV spectroscopy indicated that naphthoquinones were present. A more detailed study, using a combination of HPLC, mass spectroscopy and NMR techniques, indicated that the major respiratory lipoquinone present in this organism is a menaquinone with a fully saturated heptaprenyl side chain $\left(\mathrm{MK}-7 \mathrm{H}_{14}\right)$.
\end{abstract}

\section{INTRODUCTION}

Investigations of the respiratory lipoquinone composition of eubacteria have shown that lipoquinones serve as useful chemotaxonomic markers (see Collins \& Jones, 1981 for a review). Studies on aerobic archaebacteria have shown that Thermoplasma contains MK-7 and MMK-7, while members of the family Halobacteriaceae have $\mathrm{MK}-8$ and $\mathrm{MK}-8 \mathrm{H}_{2}$ as the major lipoquinones (Collins, 1985; Collins \& Langworthy, 1983; Collins et al., 1981). In contrast, members of the genera Sulfolobus and Acidianus synthesize an unusual series of benzo-[b]thiophen-4,7-quinones with fully or partially saturated C6 side chains (Collins \& Langworthy, 1983; De Rosa et al., 1977; Lanzotti et al., 1986; Segerer et al., 1986; Thurl et al., 1986). Studies on anaerobic, thermophilic archaebacteria have shown that Thermoproteus tenax contains a menaquinone with a fully saturated hexaprenyl C3 side chain $\left(\mathbf{M K}-6 \mathrm{H}_{12}\right)$, but that Thermococcus celer, Desulfurococcus mucosus and Desulfurococcus mobilis are devoid of lipoquinones (Thurl et al., 1985, 1986). Despite the lack of published information on the methanogenic archaebacteria there is no evidence to suggest that lipoquinones are present in any of the organisms examined to date (M. D. Collins, unpublished; B. J. Tindall, unpublished).

A new type of thermophilic archaebacterium, Archaeoglobus fulgidus, capable of sulphate reduction, has recently been isolated (Achenbach-Richter et al., 1987; Stetter, 1988; Stetter et al., 1987). Studies on the biochemistry and phylogenetic position of this organism suggest that it may represent a novel archaebacterial branch. In particular, it has been suggested that Archaeoglobus fulgidus may occupy an evolutionary position intermediate between the methanogenic and the thermophilic, sulphur-respiring, branches of the archaebacteria. Considering some of its unusual properties it was of interest to examine this organism for the

$\dagger$ Present address: Deutsche Sammlung von Mikroorganismen und Zellkulturen GmbH, Mascheroder Weg 1b, D-3300 Braunschwieg, Federal Republic of Germany.

Abbreviations: MK- $n$, menaquinone with $n$ isoprene units; MMK- $n$, methylmenaquinone with $n$ isoprene units; $\mathrm{MK}-n \mathrm{H}_{x}$, menaquinone with saturation in the isoprene side chain. 
presence of respiratory lipoquinones. The present paper reports on the structure of the respiratory lipoquinone isolated from the cell membranes of Archaeoglobus fulgidus.

\section{METHODS}

Organism and growth conditions. Archaeoglobus fulgidus (strain VC-16, DSM 4304) was grown anaerobically in the presence of sulphate and lactate in the marine medium described previously (Stetter et al., 1987). Following harvesting of the cells in a continuous-flow centrifuge, the cell pellet was disrupted by sonication, and the cell membranes collected by ultracentrifugation (Speich \& Trüper, 1988). The membranes were freeze-dried and examined for their respiratory lipoquinone content.

Extraction and purification of the lipoquinones. Freeze-dried cell membranes were extracted by a modification of the method of Redfearn (1967), using methanol/hexane $(2: 1, \mathrm{v} / \mathrm{v})$. The cell membranes were extracted for $1 \mathrm{~h}$, and the lipoquinone material partitioned into hexane by the addition of 1 vol. hexane. After decanting the hexane layer, extraction was continued for a further $30 \mathrm{~min}$, followed by the addition of 1 vol. hexane and $0 \cdot 1$ vol. $0 \cdot 3 \%$ $(\mathrm{w} / \mathrm{v})$ aqueous $\mathrm{NaCl}$. The hexane phases were combined, concentrated in a rotary evaporator, and the lipoquinones purified on silica gel thin-layer plates developed in hexane/tert-butyl methyl ether $(9: 1, \mathrm{v} / \mathrm{v})$. Quantitative analysis of the lipoquinone mixture was carried out using an LDC/Milton Roy HPLC equipped with a CI-10 integrator. Lipoquinones were separated on an ODS- 2 column $(250 \times 4.6 \mathrm{~mm})$, using methanol as mobile phase, and with detection at $269 \mathrm{~nm}$.

Physicochemical analyses. UV spectra were recorded in iso-octane using a Beckman ACTA MVI spectrophotometer. Mass spectra were recorded on an AEI MS50 instrument, employing a direct insertion probe, an ionizing voltage of $70 \mathrm{eV}$, and a temperature of $180{ }^{\circ} \mathrm{C} .{ }^{1} \mathrm{H}-\mathrm{NMR}$ and ${ }^{13} \mathrm{C}-\mathrm{NMR}$ spectra were recorded on a Brucker WH500 spectrometer using $\mathrm{CDCl}_{3}$ as solvent. A 2-D COSY-45 spectrum was run using $2 \mathrm{~K} \times 2 \mathrm{~K}$ data points, with sine-bell windows and symmetrication. Multiplicities were determined by the DEPT method.

\section{RESULTS AND DISCUSSION}

Extraction of the cell membranes using the method of Collins (1986) or a modified method of Redfearn (1967), and subsequent examination for the presence of a respiratory lipoquinone by silica gel thin-layer chromatography, revealed the presence of a single UV-absorbing band cochromatographing with an authentic menaquinone standard. Examination of the UV spectrum of this material in iso-octane showed absorption maxima at 242, 248, 260, 269 and $326 \mathrm{~nm}$, typical of menaquinones (Collins, 1986). Analysis of the menaquinone mixture by HPLC indicated that about $98 \%$ of the material was a menaquinone with a retention time $(59.5 \mathrm{~min})$ considerably greater than that of MK-7 (15.2 min) and MK-8 (21.5 min) standards.

Mass spectral analysis of the major lipoquinone revealed a comparatively simple fragmentation pattern, with intense peaks at $m / z 662\left(\mathrm{M}^{+}\right)$and at $m / z 187$. A less intense peak at $m / z 648$ could be attributed to the loss of a $\mathrm{CH}_{3}$ group from the naphthoquinone nucleus. The lack of fragmentation in the region $\mathrm{m} / z 187$ to 648 was indicative of the absence of unsaturation in the C3 isoprenoid side chain (Thurl et al., 1985, 1986). In fully or partially saturated lipoquinones isolated to date, the first isoprene unit is unsaturated, which results in cleavage of the side chain at $C^{\prime} 1-C^{\prime} 2$ and $C^{\prime} 3-C^{\prime} 4$ and produces the characteristic peaks at $m / z 187$ and 225 , attributable to the naphthoquinone nucleus. In the absence of a double bond at the first isoprenoid unit, cleavage at $\mathrm{C}^{\prime} 3-\mathrm{C}^{\prime} 4$ does not occur, and the absence of a peak at $\mathrm{m} / \mathrm{z} 225$ provides a rapid method for detecting menaquinones with saturation in the first isoprene unit (Thurl et al., 1985). Similarly, fully unsaturated lipoquinones show cleavage at diallylic bonds, giving a characteristic cleavage pattern based on the rule $\left(\mathrm{M}^{+}-69\right)-68 \times(n-1)$. In the absence of such a fragmentation pattern and the lack of a peak at $m / z 225$ this suggests that the major lipoquinone is a menaquinone with a fully saturated side chain, consisting of seven isopranyl units (Fig. 1). Examination of the mass spectrum of the menaquinone mixture also revealed the presence of a second lipoquinone in small amounts, with a molecular ion $\left(\mathrm{M}^{+}\right)$at $m / z 592$, indicating the presence of a fully saturated menaquinone with six isopranyl units.

${ }^{1} \mathrm{H}-\mathrm{NMR}$ studies confirmed the presence of a 2-methyl-1,4-naphthoquinone ring nucleus, with resonances at $\delta 2.177$ (singlet; methyl at $\mathrm{C} 2$ ), $87.65-7.7$ (multiplet; $\mathrm{C} 6$ and C7), and at 88.04-8.I (multiplet; C5 and C8). Resonances due to the isoprenoid C3 side chain showed the absence of unsaturation. The presence of a multiplet centred at $\delta 2.61$ ( $\mathrm{C}^{\prime} 1$; aliphatic methylene) 
<smiles>CC(C)CCCC(C)CCCC(C)CCCC(C)CCCC(C)CCCC(C)CCCC(C)CCC1=C(C(C)(C)C)C(=O)c2ccccc2C1=O</smiles>

Fig. 1. Structure and mass spectral fragmentation pattern of the novel menaquinone from Archaeoglobus fulgidus. The major peaks in the mass spectrum may be attributed to the molecular ion $\left(\mathrm{M}^{+} ; m / z 662\right)$, the loss of the $\mathrm{C} 2$ methyl $(1 ; m / z 648)$, and cleavage at $\mathrm{C}^{\prime} 1-\mathrm{C}^{\prime} 2(2 ; m / z 187)$.

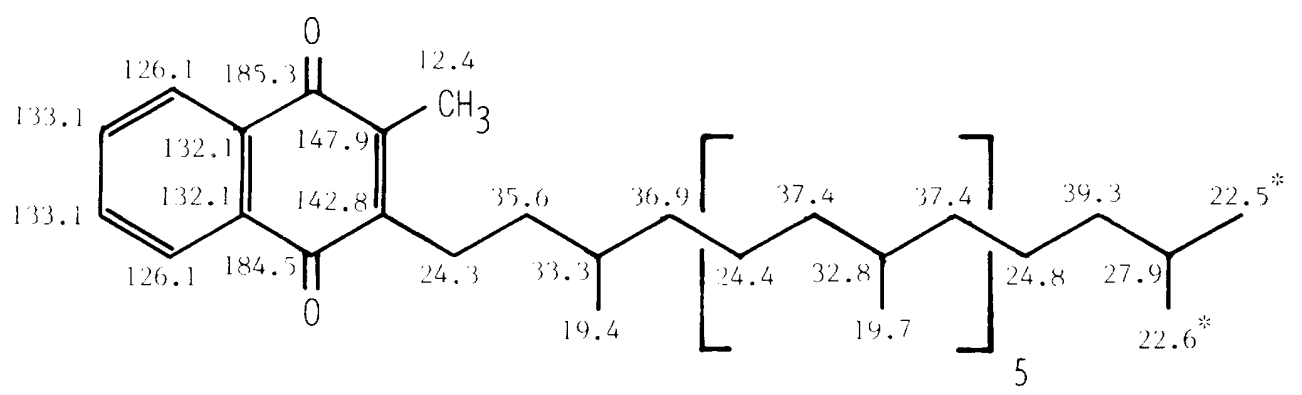

Fig. 2. Allocation of the ${ }^{13} \mathrm{C}-\mathrm{NMR}$ signals obtained from the menaquinone from Archaeoglobus fulgidus. Values are expressed as p.p.m. The two signals marked * are interchangeable.

and a doublet at $\delta 0 \cdot 975$ (aliphatic methyl; first isoprene unit) confirm that the first isoprene unit is saturated. Menaquinones containing an unsaturated first isoprene unit are characterized by the presence of a doublet at $\delta 3.36\left(\mathrm{C}^{\prime} 1\right.$; alyllic methylene) and a singlet at $\delta 1.77$ (trans-methyl; first isoprene unit). Saturation in the terminal (end of chain) isoprene unit was confirmed by the presence of a doublet at $\delta 0 \cdot 850$ (two equivalent terminal methyls) and the absence of a signal due to $c i s$-end of chain methyls (singlet at $\delta 1.667$ ). Resonances centred at $\delta 0.83$ (internal aliphatic methyls) had an integral of 5 , and taken together with the absence of resonances in the region $\delta 4 \cdot 85-5 \cdot 1$, attributable to unsaturation, confirm the presence of a fully saturated heptapranyl $\mathrm{C} 3$ side chain. COSY-45 ${ }^{1} \mathrm{H}-\mathrm{NMR}$ spectra of the isopranyl side chain region confirm these structural conclusions.

${ }^{13} \mathrm{C}-\mathrm{NMR}$ of the lipoquinone (Fig. 2) provided further, confirmatory evidence for the nature of the major lipoquinone in this organism. Resonances attributable to carbon atoms in the naphthoquinone ring nucleus are consistent with the presence of a 2-methyl-3-polyisoprenyl-1,4naphthoquinone. All remaining signals were in the region 19.4-39.3 p.p.m., indicating that only aliphatic methines, methylenes and methyls were present. Resonances for carbon-carbon double bonds are found at higher values, and these data provide conclusive proof for the presence of a fully saturated C3 isopranyl side chain.

The data presented provide unequivocal evidence for the structure of the major lipoquinone from the cell membranes of Archaeoglobus fulgidus. The UV spectrum, mass spectra, ${ }^{1} \mathrm{H}-$ and ${ }^{13} \mathrm{C}$-NMR data are consistent with the presence of a 2-methyl-3-polyisoprenyl-1,4-naphthoquinone. The characteristic fragmentation pattern of the major lipoquinone in the mass spectrometer indicates the absence of unsaturation in the isoprene side chain. It has already been shown that in partially or fully unsaturated lipoquinones the absence of predicted peaks in the isoprenoid fragmentation pattern is indicative of the points of saturation (Collins, 1986). In the absence of such a fragmentation pattern it may be concluded from the mass spectrum that the $\mathrm{C} 3$ side chain is fully saturated. Data provided from the ${ }^{1} \mathrm{H}-\mathrm{NMR}$ and ${ }^{13} \mathrm{C}-\mathrm{NMR}$ are in agreement with the proposed structure.

The data indicate that the major respiratory lipoquinone present in the archaebacterium Archaeoglobus fulgidus is a fully saturated menaquinone homologue, and corresponds to 
2-methyl-3-I,II,III,IV,V,VI,VII-tetradecahydro-heptaprenyl-1,4-naphthoquinone (MK-7 $\left.\mathrm{H}_{14}\right)$

(Fig. 1).

This study shows that the archaebacterial sulphate-reducer, Archaeoglobus fulgidus, like its eubacterial sulphate-reducing counterparts, contains a menaquinone as the major respiratory lipoquinone (Collins \& Widdel, 1986). However, examination of the menaquinone composition of eubacterial sulphate-reducers has shown that the $\mathrm{C} 3$ isoprenoid side chains of the lipoquinones in these organisms are either fully unsaturated, or dihydrogenated in the terminal isoprenoid unit. In contrast, the presence of a fully saturated side chain in the menaquinone from Archaeoglobus fulgidus indicates similarities to Thermoproteus tenax and the fully saturated side chains found in 'Caldariella-' and 'Sulfolobus-quinone'. This feature of a fully saturated C3 side chain in the respiratory lipoquinones of certain archaebacteria may prove to be a characteristic marker for one branch of the archaebacterial lineage. Further studies are in progress to test this hypothesis.

This work was carried out with the financial support of grants from the Deutsche Forschungsgemeinschaft to H. G. Trüper and to K. O. Stetter. We would like to thank G. Lauerer (Regensburg) for culturing the cells, N. Speich (Bonn) for making the cell membranes available, and Dr Eckhardt (Bonn) for assistance with the mass spectral studies.

\section{REFERENCES}

ACHenbach-Richter, L., Stetter, K. O. \& Woese, C. R. (1987). A possible biochemical missing link among archaebacteria. Nature, London 327, 348-349.

Collins, M. D. (1985). Structure of thermoplasma quinone from Thermoplasma acidophilum. FEMS Microbiology Letters 28, 21-23.

Collins, M. D. (1986). Analysis of isoprenoid quinones. Methods in Microbiology 18, 329-366.

COLlins, M. D. \& JoNES, D. (1981). Distribution of isoprenoid quinone structural types in bacteria and their structural implications. Microbiological Reviews 45, 316-354.

Collins, M. D. \& Langworthy, T. A. (1983). Respiratory quinone composition of some acidophilic bacteria. Systematic and Applied Microbiology 4, 295-304.

Collins, M. D. \& Widdel, F. (1986). Respiratory quinones of sulphate-reducing and sulphur-reducing bacteria: a systematic investigation. Systematic and Applied Microbiology 8, 8-18.

Collins, M. D., Ross, H. N. M., Tindall, B. J. \& Grant, W. D. (1981). Distribution of quinones in halophilic bacteria. Journal of Applied Bacteriology 50, 559-565.

Da Rosa, M., De Rosa, S., Gambacorta, A., Minale, L., Thomson, R. H. \& Worthington, R. D. (1977). Caldariellaquinone, a unique benzo-b-thiophen-4,7quinone from Caldariella acidophila, an extremely thermophilic and acidophilic bacterium. Journal of the Chemical Society Perkin Transactions 1, 653-657.

Lanzotti, V., Tricone, A., Gambacorta, A., De Rosa, M. \& Breitmaier, E. (1986). ${ }^{1} \mathrm{H}$ and ${ }^{13} \mathrm{C}$
NMR assignments of benzothiophenquinones from the sulfur-oxidising archaebacterium Sulfolobus solfataricus. European Journal of Biochemistry 160, $37-40$.

REDFEARN, E. R. (1967). Isolation and distribution of ubiquinones. Methods in Enzymology 10, 381-384.

Segerer, A., Neuner, A., Kristjansson, J. K. \& STETTER, K. O. (1986). Acidianus infernus gen. nov., sp. nov., and Acidianus brierleyi comb. nov.: facultatively aerobic, extremely acidophilic thermophilic sulfur-metabolizing archaebacteria. International Journal of Systematic Bacteriology 36, 559-564.

SPEICH, N. \& TRÜPER, H. G. (1988). Adenylylsulphate reductase in a dissimilatory sulphate-reducing archaebacterium. Journal of General Microbiology 134, 1419-1425.

SteTtER, K. O. (1988). Archaeoglobus fulgidus gen. nov., sp. nov.: a new taxon of extremely thermophilic archaebacteria. Systematic and Applied Microbiology 10, 172-173.

Stetter, K. O., Lauerer, G., Thomm, M. \& Neuner, A. (1987). Isolation of extremely thermophilic sulfate-reducers: evidence for a novel branch of archaebacteria. Science 236, 822-824.

Thurl, S., Buhrow, I. \& SchäfER, W. (1985). New types of menaquinones from the thermophilic archaebacterium Thermoproteus tenax. Biological Chemistry Hoppe-Seyler 366, 1079-1083.

Thurl, S., Witke, W., BuHrow, I. \& SCHÄFER, W. (1986). Different types of quinones from sulphurdependent archaebacteria. Biological Chemistry Hoppe-Seyler 367, 191-197. 